\title{
Proposal for a Protocol for Awake Fiberoptic Intubation in Adult with Dexmedetomidine
}

\author{
Eugenio D. Martínez-Hurtado ${ }^{1 *}$, Míriam Sánchez-Merchante ${ }^{2}$ and Manuel Ángel Gómez-Ríos ${ }^{3}$ \\ ${ }^{1}$ Consultant Anaesthetist at Infanta Leonor University Hospital, Department of Anesthesia and Intensive Care, Madrid, Spain \\ ${ }^{2}$ Consultant Anaesthetist at Alcorcon Foundation University Hospital, Department of Anesthesia and Intensive Care, Madrid, Spain \\ ${ }^{3}$ Consultant Anesthesiologist at Complejo Hospitalario Universitario de A Coruña, Spain
}

Received: June 06, 2017; Accepted: August 17, 2017, Published: September 05, 2017

*Corresponding author: Eugenio D. Martínez-Hurtado, Consultant Anaesthetist at Infanta Leonor University Hospital, Department of Anesthesia and Intensive Care, Av. Gran Vía del Este, 80, 28031, Madrid, Spain, Tel.:0034620283465;Fax:0034911918000;E-mail:eugeniodaniel.martinez@ salud.madrid.org

\section{Introduction - Abstract}

Fiberoptic intubation with the awakened patient (Awake Fibreoptic Intubation [AFOI]) is the gold standard technique for difficult airway management. The threshold for adopting AFOI depends, to some extent, on the competence of the person who will perform the intubation. The technique frequently requires sedation, anxiolysis and relief of discomfort without impairing ventilation and depressing cardiovascular function, a patent airway with blunting reflexes and spontaneous ventilation, especially when the airway is difficult. Many agents like fentanyl, midazolam, ketamine, propofol and remifentanil have been used to facilitate AFOI, but dexmedetomidine, $\alpha 2$ adrenoreceptor agonist with combined sedative, analgesic, anxiolytic and sympatholytic properties and without significantly depress effect over the ventilatory drive, has many properties to make it suitable for use during this technique.

The management of difficult airway is one of the most challenging tasks for the anesthesiologist. Awake Fibreoptic Intubation (AFOI) still is underutilized because some patients will reject AFOI and others, particularly children, may be unable to cooperate (1). Moreover, fibreoptic intubation is a procedure which requires familiarity with the equipment and an understanding of airway endoscopic anatomy (2).

In patients with a possible or secure difficult airway, such as those presenting positive predictors, deformities or tumors in the airway, airway lesions, instability of the spinal cord, or antecedents of a previous difficult airway, AFOI is an effective and reliable technique to manage the difficult airway. In such situation, AFOI requires proficiency in providing efficient topical anesthesia and sedation techniques during the procedure in order to maintain the patient's airway cooperation and reduced anxiety, minimizing discomfort or serious adverse effects during the procedure (3).
Sedation may be used effectively to calm anxious patients sufficiently to obtain optimal conditions for AFOI should enable the patients to be cooperative, comfortable and have blunted airway reflexes, particularly when difficult laryngeal anatomy and/or pathology are encountered.

Many agents, including fentanyl, remifentanil, midazolam and propofol, have been reported to assist with AFOI. However, these agents can cause respiratory arrest, loss of or reduced (heart) function, especially when used in high doses, thus increasing the of low oxygen levels (hypoxemia), aspiration, low blood pressure (hypotension) or slow heart rate (bradycardia). Ideally, sedation should be administered by another anesthetist and its effects closely monitored. An awake, calm, alert patient will follow commands and can aid the intubator by taking deep breaths or protruding their tongue.

Different protocols for sedation have been shown to improve the success rate (4-8). There are a number of advantages of using remifentanil for AFOI. Firstly, remifentanil is an ultra-short acting drug with a constant half-life. The drug exerts antitussive effects that help to prevent coughing with tracheal manipulation. In addition, remifentanil attenuates cardiovascular responses to airway manipulation (9).

But classical methods of sedation for fiberoptic intubation, such as benzodiazepines or remifentanil, have their limitations, as demonstrated 4th National Audit Project of The Royal College of Anaesthetists (NAP4) (10). Over-sedation increases the likelihood of airway obstruction which makes endoscopy more difficult and contributes to failure. Similarly, apnea occurs increasingly with deeper sedation bringing with it some of the same risks as intentional general anaesthesia. In NAP4 there were several reports of problems when remifentanil was used in combination with other drugs for sedation. Problems noted during these events that may have been due to remifentanil included respiratory depression, apnea and delayed respiratory arrest. It was the impression of the review panel that remifentanil 
was more likely than other sedatives to cause these types of events but this remains unclear.

Dexmedetomidine hydrochloride is a sterile, nonpyrogenic solution suitable for intravenous infusion following dilution. Dexmedetomidine hydrochloride is chemically described as (+)-4-(S)-[1-(2,3-dimethylphenyl)ethyl]-1 H-imidazole monohydrochloride and has a molecular weight of 236.7 and the empirical formula is $\mathrm{C} 13 \mathrm{H} 16 \mathrm{~N} 2 \cdot \mathrm{HCl}$. (Figure1.- molecule of Dexmedetomidine hydrochloride) (11).

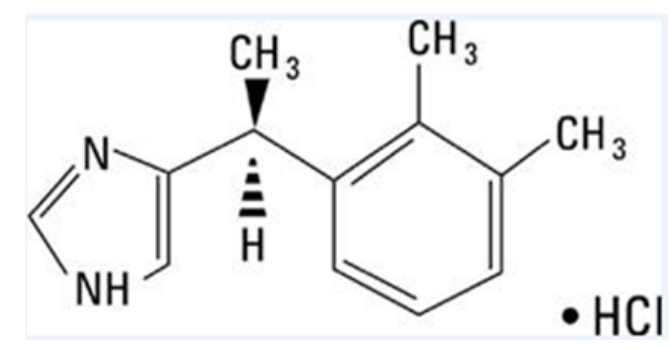

Figure 1: Molecule of Dexmedetomidine (33).

Dexmedetomidine was approved by the Food and Drug Administration at the end of 1999 for use in humans as a shortterm medication $(<24$ hours) for analgesia and sedation in the Intensive Care Unit (ICU), and in 2008 for sedation in nonintubated patients.

Its unique properties render it suitable for sedation and analgesia during the whole perioperative period. Its applications as a premedication, as an anesthetic adjunct for general and regional anesthesia, and as a postoperative sedative and analgesic are similar to those of the benzodiazepines, but a closer look reveals that the $\alpha 2$-adrenoceptor agonist has more beneficial side effects $(12,13)$.

It is a highly selective, potent $\alpha 2$ adrenergic agonist. It has sedative, analgesic and anxiolytic properties, and reduced salivary secretion, with minimal respiratory depression. And has been used clinically for its sympatholytic, analgesic and sedative effects (14-17).

Dexmedetomidinedoesnotcauseclinicallyrelevantrespiratory depression and provide hemodynamic and sympathoadrenal stability by reducing the circulating catecholamines, attenuating the response to endotracheal intubation but without completely abolish the cardiovascular response $(18,19)$. A sedation regimen using low dose dexmedetomidine combined with titrated doses of benzodiazepines and ultrashort acting narcotics with local airway anesthesia has been used for airway manipulation. A target controlled infusion can provide consistent pharmacodynamics effects with a safe and predictable sedation level (20).

Dexmedetomidine has been used for intraoperative sedation during surgery under regional anesthesia, for sedation to mechanically ventilated patients in intensive care units, and for sedation during procedures, including AFOI (21-23). In two recent trials dexmedetomidine significantly reduced patient discomfort during AFOI with no significant differences in intubation time, airway obstruction, low oxygen levels or treatment-emergent cardiovascular adverse events (24-26).

Dexmedetomidine could provide sedation and anxiolysis via receptors within the locus coeruleus, which is an important modulator of wakefulness (27). The $\alpha 2$-adrenergic receptor mediates its effects by activating guanine-nucleotide regulatory binding proteins (G proteins). Activated G proteins modulate cellular activity by signaling a second messenger system or by modulating ion channel activity.

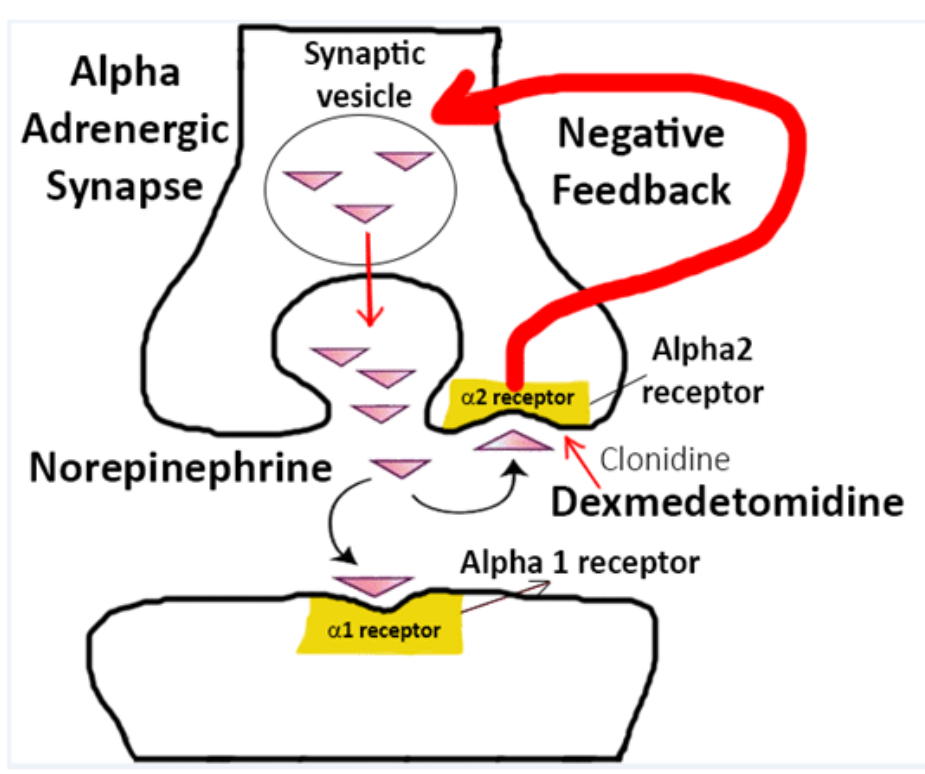

Figure 2: Physiology of the $\alpha 2$-adrenoceptor agonists receptor. 
The second messenger system, when activated, leads to the inhibition of adenylate cyclase, which, in turn, results in decreased formation of 3,5-cyclic Adenosine Monophosphate (cAMP). Specific cAMP-dependent kinases modify the activity of target proteins by controlling their phosphorylation status (28). Modulation of ion channel activity leads to hyperpolarization of the cell membrane. Efflux of potassium through an activated channel hyperpolarizes the excitable membrane and provides an effective means of suppressing neuronal firing. Stimulation of the $\alpha 2$ adrenoceptor also suppresses calcium entry into the nerve terminal, which may be responsible for its inhibitory effect on secretion of neurotransmitters. From an anesthesiologic viewpoint, neuronal hyperpolarization is a key element in the mechanism of action of $\alpha 2$-adrenoceptor agonists (29) (Figure 2).

Findings lead to the conclusion that the major sedative and antinociceptive effects of dexmedetomidine are attributable to its stimulation of the $\alpha 2$ adrenoceptors in the locus coeruleus. The locus coeruleus is also the site of origin for the descending medullospinal noradrenergic pathway, known to be an important modulator of nociceptive neurotransmission. In this region of the brain, $\alpha 2$-adrenergic and opioidergic systems have common effector mechanisms, indicating that dexmedetomidine has a supraspinal site of action.

Dexmedetomidine, an imidazole compound, is the pharmacologically active dextroisomer of medetomidine that displays specific and selective $\alpha 2$-adrenoceptor agonism. Activation of the receptors in the brain and spinal cord inhibits neuronal firing, causing hypotension, bradycardia, sedation, and analgesia. The responses to activation of the receptors in other areas include decreased salivation, decreased secretion, and decreased bowel motility in the gastrointestinal tract; contraction of vascular and other smooth muscle; inhibition of renin release, increased glomerular filtration, and increased secretion of sodium and water in the kidney, decreased intraocular pressure, and decreased insulin release from the pancreas (30).

Presynaptic activation of the $\alpha 2$ adrenoceptor inhibits the release of norepinephrine, terminating the propagation of pain signals. Postsynaptic activation of $\alpha 2$ adrenoceptors in the Central Nervous System (CNS) inhibits sympathetic activity and thus can decrease blood pressure and heart rate. Combined, these effects can produce analgesia, sedation, and anxiolysis. Dexmedetomidine combines all these effects, thus avoiding some of the side effects of multiagent therapies.

The alpha-2/alpha-1-adrenoceptor selectivity ratio is eightfold greater than for clonidine, the classic alpha-2-adrenoceptor agonist (31). Dexmedetomidine has a half-life $(\mathrm{t} 1 / 2)$ of approximately two hours, a duration of action of approximately four hours and a side effect profile that is shorter in duration than that of clonidine (i.e. much shorter influence on normal physiology) $(32,33)$.

Dexmedetomidine hydrochloride is a white or almost white powder that is freely soluble in water and has a pKa of 7.1. Its partition coefficient in-octanol: water at pH 7.4 is 2.89. Have a rapid distribution phase, with a distribution half-life (t1/2) of approximately 6 minutes, and a terminal elimination half-life (t1/2) of approximately 2 hours. Peak plasma: $0.3-1.5 \mathrm{ng} / \mathrm{mL}$. Protein bound: 94\% Vd: 118 L Metabolism: Liver, including glucuronidation and CYP2A6 Metabolites: 3-hydroxy, 3-carboxy, 3-hydroxy N-methyl, 3-carboxy N-methyl, and N-methyl 0-glucuronide dexmedetomidine. Total body clearance: $39 \mathrm{~L} / \mathrm{hr}$. The mean body weight associated with this clearance estimate was $72 \mathrm{~kg}$. Dexmedetomidine undergoes almost complete biotransformation with very little unchanged dexmedetomidine excreted in urine and feces. Biotransformation involves both direct glucuronidation as well as cytochrome P450 mediated metabolism. Excretion: Urine (95\%), feces $(4 \%)(32,33)$.

When used at higher doses, dexmedetomidine exhibits minimal respiratory depression $(34,35)$. Thus, dexmedetomidine has been proposed as a promising drug to use during AFOI for managing patients with a difficult or unstable airway (36-38). Dexmedetomidine has been approved for use in intubated and mechanically ventilated patients in the intensive care unit (ICU), as well as in non-intubated patients undergoing surgical or other procedures (30).

Although dexmedetomidine has beneficial attributes, increasing concentrations of dexmedetomidine in humans results in bradycardia and a biphasic (low, then high) dose-response relation for mean arterial pressure, especially in patients with intrinsic or drug induced bradycardia, hypovolaemia, advanced heart block or severe ventricular dysfunction (30).

Alpha selectivity is observed in animals following slow intravenous infusion of low and medium doses $(10-300 \mathrm{mcg} /$ $\mathrm{kg}$ ). Both alpha and alpha activity is observed following slow intravenous infusion of high doses $(\geq 1000 \mathrm{mcg} / \mathrm{kg})$ or with rapid intravenous administration. It is recommended that dexmedetomidine be administered at a loading dose of $1 \mathrm{mcg} / \mathrm{kg}$ for at least 10 minutes, followed by a maintenance infusion of 0.2 to $0.5 \mathrm{mcg} / \mathrm{kg} / \mathrm{h}$.

\begin{tabular}{|c|c|c|c|c|}
\hline & \multicolumn{4}{|c|}{$\begin{array}{l}\text { Loading Infusion (minutes) / Total infusion duration } \\
\text { (hours) }\end{array}$} \\
\hline & $\begin{array}{l}10 \text { min. } / 12 \\
\text { hrs. }\end{array}$ & $\begin{array}{l}10 \text { min. } / 24 \\
\text { hrs. }\end{array}$ & $\begin{array}{l}10 \min . / 24 \\
\text { hrs. }\end{array}$ & $\begin{array}{l}35 \mathrm{~min} . / 24 \\
\text { hrs. }\end{array}$ \\
\hline & \multicolumn{4}{|c|}{$\begin{array}{l}\text { Dexmedetomidine Target Concentration }(\mathrm{ng} / \mathrm{mL}) / \text { Dose } \\
(\mathrm{mcg} / \mathrm{kg} / \mathrm{hr})\end{array}$} \\
\hline & $\begin{array}{c}0.3 \mathrm{ng} / \mathrm{mL} \\
/ 0.17 \mathrm{mcg} / \\
\mathrm{kg} / \mathrm{hr}\end{array}$ & $\begin{array}{c}0.3 \mathrm{ng} / \mathrm{mL} \\
/ 0.17 \mathrm{mcg} / \\
\mathrm{kg} / \mathrm{hr}\end{array}$ & $\begin{array}{c}0.6 \mathrm{ng} / \mathrm{mL} \\
/ 0.33 \mathrm{mcg} / \\
\mathrm{kg} / \mathrm{hr}\end{array}$ & $\begin{array}{c}1.25 \mathrm{ng} / \\
\mathrm{mL} / 0.70 \\
\mathrm{mcg} / \mathrm{kg} / \mathrm{hr}\end{array}$ \\
\hline$t^{1 / 2} *^{*}$, hour & $1.78 \pm 0.30$ & $2.22 \pm 0.59$ & $2.23 \pm 0.21$ & $2.50 \pm 0.61$ \\
\hline $\begin{array}{l}\text { CL, litre/ } \\
\text { hour }\end{array}$ & $46.3 \pm 8.3$ & $43.1 \pm 6.5$ & $35.3 \pm 6.8$ & $36.5 \pm 7.5$ \\
\hline Vss, litre\& & $88.7 \pm 22.9$ & $102.4 \pm 20.3$ & $93.6 \pm 17.0$ & $99.6 \pm 17.8$ \\
\hline $\begin{array}{l}\text { AvgCss \#, } \\
\mathrm{ng} / \mathrm{mL}\end{array}$ & $0.27 \pm 0.05$ & $0.27 \pm 0.05$ & $0.67 \pm 0.10$ & $1.37 \pm 0.20$ \\
\hline \multicolumn{5}{|c|}{$\begin{array}{l}\text { * Presented as harmonic mean and pseudo standard deviation. } \\
\text { \& Vss = volume of distribution at steady state } \\
\text { \# Avg Css = Average steady-state concentration of dexmedetomidine. } \\
\text { ( } 2.5 \text { - } 9 \text { hour samples for } 12 \text { hour infusion and } 2.5 \text { - } 18 \text { hour samples } \\
\text { for } 24 \text { hour infusions). }\end{array}$} \\
\hline
\end{tabular}


Dexmedetomidine exhibits linear kinetics in the dosage range of 0.2 to $0.7 \mathrm{mcg} / \mathrm{kg} / \mathrm{hr}$ when administered by IV infusion for up to 24 hours. Table 1 shows the main pharmacokinetic parameters when Dexmedetomidine is infused (after appropriate loading doses) at maintenance infusion rates of $0.17 \mathrm{mcg} / \mathrm{kg} / \mathrm{hr}$ (target concentration of $0.3 \mathrm{ng} / \mathrm{mL}$ ) for 12 and 24 hours, $0.33 \mathrm{mcg} / \mathrm{kg} / \mathrm{hr}$ (target concentration of $0.6 \mathrm{ng} / \mathrm{mL}$ ) for 24 hours, and $0.70 \mathrm{mcg} /$ $\mathrm{kg} / \mathrm{hr}$ (target concentration of $1.25 \mathrm{ng} / \mathrm{mL}$ ) for 24 hours $(32,33)$.

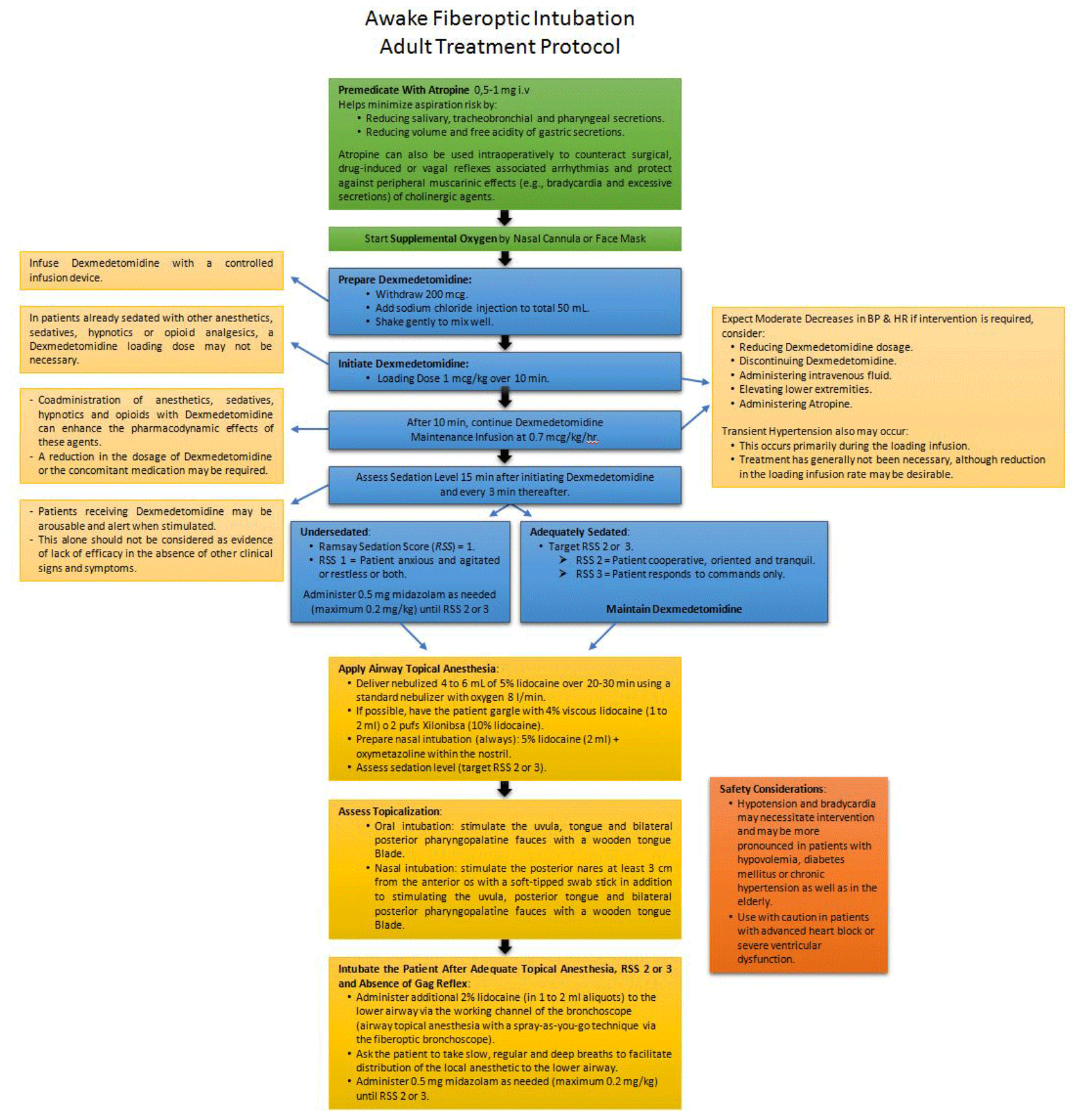

Figure 3: Awake Fiberoptic Intubation - Adult Treatment Protocol

Citation: Eugenio DMH, Míriam SM, et al. (2017) Proposal for a Protocol for Awake Fiberoptic Intubation in Adult with

Dexmedetomidine. SOJ Anesthesiol Pain Manag. 4(2): 1-7. 
In this context, we propose the following protocol Awake Fiberoptic Intubation in Adults (Figure 3.- Awake Fiberoptic Intubation - Adult Treatment Protocol). It is a proposal that tries to combine Dexmedetomidine with the protocol for Awake Intubation of the Madrid Anesthesia and Reanimation Society (SAR Madrid) that we usually use (39).

The effect of continuous infusion begins at 15 minutes and reaches the plateau in 1 hour. No dose adjustment is required in presence of renal failure or in the elderly. The most frequent adverse effects are hypotension and bradicardia $(32,33)$.

\section{Habitual dosage (Table 2):}

-Initial dose: $0.7 \mathrm{mcg} / \mathrm{kg} / \mathrm{hr}$.

-Dosage range: $0.2-1.4 \mathrm{mcg} / \mathrm{kg} / \mathrm{hr}$.

-Usual dose: $0.5 \mathrm{mcg} / \mathrm{kg} / \mathrm{hr}$.

-Drug presentations in our hospital are Ampoules of 2 with 100 $\mathrm{mcg} / \mathrm{ml}$ (200 mcg per ampoule), or $10 \mathrm{ml}$ ampoules with 100 $\mathrm{mcg} / \mathrm{ml}(1000 \mathrm{mcg}$ per ampoule $=1 \mathrm{mg})$.

-Cost in Spain: 4 ampoules of $10 \mathrm{ml}$ have an approximate cost of 360 euros.

Table 2: Calculate IV rate as $\mathrm{mL} / \mathrm{hr}$. of Dexmedetomidina as a function of the weight and dose administered.

\begin{tabular}{|c|c|c|c|c|c|c|c|c|c|c|}
\hline \multirow[t]{2}{*}{ Weight (kg.) } & \multicolumn{10}{|c|}{ Dosage $(\mathrm{mcg} / \mathrm{kg} / \mathrm{h})$} \\
\hline & 0.2 & 0.4 & 0.5 & 0.6 & 0.7 & 0.8 & 1 & 1.2 & 1.4 & \\
\hline 40 & 0.4 & 0.7 & 1 & 1.1 & 1.3 & 1.5 & 2 & 2.4 & 2.8 & \multirow{13}{*}{$\begin{array}{l}\text { IV rate } \\
(\mathrm{ml} / \mathrm{h})\end{array}$} \\
\hline 45 & 0.5 & 0.8 & 1.1 & 1.3 & 1.5 & 1.7 & 2.2 & 2.6 & 3.2 & \\
\hline 50 & 0.5 & 1 & 1.2 & 1.5 & 1.7 & 2 & 2.5 & 3 & 3.4 & \\
\hline 55 & 0.6 & 1.1 & 1.5 & 1.6 & 2 & 2.2 & 2.8 & 3.3 & 3.8 & \\
\hline 60 & 0.6 & 1.2 & 1.5 & 1.8 & 2.1 & 2.4 & 3 & 3.5 & 4.2 & \\
\hline 65 & 0.7 & 1.3 & 1.6 & 2 & 2.3 & 2.6 & 3.2 & 4 & 4.5 & \\
\hline 70 & 0.7 & 1.4 & 1.7 & 2.2 & 2.5 & 2.8 & 3.5 & 4.2 & 4.8 & \\
\hline 75 & 0.8 & 1.5 & 1.8 & 2.2 & 2.6 & 3 & 3.8 & 4.5 & 5.2 & \\
\hline 80 & 0.9 & 1.5 & 2 & 2.5 & 3 & 3.3 & 4 & 4.8 & 5.5 & \\
\hline 85 & 1 & 1.8 & 2.2 & 2.6 & 3.1 & 3.5 & 4.2 & 5 & 6 & \\
\hline 90 & 1.1 & 1.9 & 2.3 & 2.7 & 3.2 & 3.6 & 4.5 & 5.4 & 6.2 & \\
\hline 95 & 1.1 & 2 & 2.5 & 2.9 & 3.4 & 3.8 & 4.8 & 5.6 & 6.5 & \\
\hline 100 & 1.2 & 2.2 & 2.6 & 3 & 3.5 & 4 & 5 & 6 & 7 & \\
\hline
\end{tabular}

1. Dilution: 1 ampoule of $10 \mathrm{ml}(1,000 \mathrm{mcg}=1 \mathrm{mg})$ in $40 \mathrm{ml}$ of sodium chloride ( $50 \mathrm{~mL}$ total $=20 \mathrm{mcg} / \mathrm{ml}=0.002 \mathrm{mg} / \mathrm{ml})$.

2. Adjust the dose to achieve a RSS 2 - 3 (table 3 and figure 3):

a. Start the infusion at $1 \mathrm{mcg} / \mathrm{kg} / \mathrm{h}(2-5 \mathrm{ml} / \mathrm{hr}$ ) over $10 \mathrm{~min}$ (Loading Dose).

b. After $10 \mathrm{~min}$, continue at $0.7 \mathrm{mcg} / \mathrm{kg} / \mathrm{hr}(1.3-3.5 \mathrm{ml} / \mathrm{h}$ ) (Maintenance Infusion).

c. After 5 min (15 min after initiating infusion) and every 3 min thereafterAssess Sedation Level. Target à RSS 2 - 3:

i. Usual dose $0.5 \mathrm{mcg} / \mathrm{kg} / \mathrm{hr}(1-2.6 \mathrm{ml} / \mathrm{h})$.

ii. Usual dosage range: $0.4-0.7 \mathrm{mcg} / \mathrm{kg} / \mathrm{hr}(0.7-3.5 \mathrm{ml} / \mathrm{hr})$.

3. Do not exceed the dose of $1.4 \mathrm{mcg} / \mathrm{kg} / \mathrm{hr}(2.8-7 \mathrm{ml} / \mathrm{hr})$.

Table 3: Ramsey Sedation Scale (RSS) (40)

If Awake

\begin{tabular}{|c|c|}
\hline - Ramsey 1 & Anxious, agitated, restless \\
\hline - $\quad$ Ramsey 2 & Cooperative, oriented, tranquil \\
\hline - Ramsey 3 & Responsive to commands only \\
\hline \multicolumn{2}{|l|}{ If Asleep } \\
\hline - Ramsey 4 & Brisk response to light glabellar (between eyebrows) tap or loud auditory stimulus \\
\hline - $\quad$ Ramsey 5 & Sluggish response to light glabellar tap or loud auditory stimulus \\
\hline - Ramsey 6 & No response to light glabellar tap or loud auditory stimulus \\
\hline
\end{tabular}


The degree of sedation of the patient is determined by the Ramsay Sedation Scale (Table 3) (40).

But we must remember that it is not a harmless drug. Dexmedetomidine should be administered only by persons skilled in the management of patients in the intensive care or operating room setting. Due to the known pharmacological effects of Dexmedetomidine, patients should be continuously monitored while receiving Dexmedetomidine.

Caution should be exercised when administering Dexmedetomidine to patients with advanced heart block and/ or severe ventricular dysfunction. Because Dexmedetomidine decreases sympathetic nervous system activity, hypotension and/or bradycardia may be expected to be more pronounced in patients with hypovolemia, diabetes mellitus, or chronic hypertension and in elderly patients (33).

Some patients receiving Dexmedetomidine have been observed to be arousable and alert when stimulated. This alone should not be considered as evidence of lack of efficacy in the absence of other clinical signs and symptoms.

In terms of adverse reactions, rates observed in the clinical trials of a drug cannot be directly compared to rates in studies of another drug, and may not reflect the rates observed in practice. Use of Dexmedetomidine has been associated with the following serious adverse reactions:

I. Hypotension, bradycardia and sinus arrest. Clinically significant episodes of hypotension, bradycardia and sinus arrest have been reported with Dexmedetomidine administration in young, healthy adult volunteers with high vagal tone or with different routes of administration including rapid intravenous or bolus administration. If medical intervention is required, treatment may include decreasing or stopping the infusion of Dexmedetomidine, increasing the rate of intravenous fluid administration, elevation of the lower extremities, and use of pressor agents. Because Dexmedetomidine has the potential to augment bradycardia induced by vagal stimuli, clinicians should be prepared to intervene. The intravenous administration of anticholinergic agents (e.g., atropine) should be considered to modify vagal tone. In clinical trials, glycopyrrolate or atropine were effective in the treatment of most episodes of Dexmedetomidineinduced bradycardia. However, in some patients with significant cardiovascular dysfunction, more advanced resuscitative measures were required.

II. Transient hypertension has been observed primarily during the loading dose in association with the initial peripheral vasoconstrictive effects of Dexmedetomidine. Treatment of the transient hypertension has generally not been necessary, although reduction of the loading infusion rate may be desirable.

Most common treatment-emergent adverse reactions, occurring in greater than $2 \%$ of patients in both Intensive Care Unit and procedural sedation studies, include hypotension, bradycardia and dry mouth (13).

Respect to the risk of over dosage, the tolerability of
Dexmedetomidine has been established in a recommended dose of 0.2 to $0.7 \mathrm{mcg} / \mathrm{kg} / \mathrm{hr}$. in one study with healthy adult subjects. Doses above approximately 13 times the upper boundary of the therapeutic originate first degree atrioventricular block and second degree heart block. No hemodynamic compromise was noted with the atrioventricular block and the heart block resolved spontaneously within one minute $(13,15,17,26,32,33)$.

Contraindications: Hypersensitivity to Dexmedetomidine.

-Second or third-degree AV block without pacemaker.

-Bradycardia $<55$ bpm.

-Fluid refractory hypotension and need for noradrenaline at doses $>0.5 \mathrm{mcg} / \mathrm{kg} /$ minute.

-Dysautonomy (e.g. spinal cord injury).

In conclusion, as all we know where FOI is considered the optimal method of securing the airway, an awake technique should be considered unless contraindicated. But AFOI can fail due to a number of factors including poor co-operation, inappropriate sedation, bleeding and inability to identify anatomy and airway obstruction. Fibreoptic intubation is most effective in co-operative patients. Airway patency and co-operation may be lost by over-sedation. Where complex sedation techniques are to be used, strong consideration should be given to delegating the provision of sedation to an anaesthetist not performing the tracheal intubation.

Dexmedetomidine is a highly selective, potent $\alpha 2$ adrenergic agonist, with sedative, analgesic and anxiolytic properties that reduced salivary secretion with minimal respiratory depression. So that it seems to be a good option... and only time will tell us if it displaces the other techniques.

\section{References}

1. Benumof JL. Management of the difficult airway: with special emphasis on awake tracheal intubation. Anesthesiology. 1991;75(6):1087-1110.

2. Popat M, Rai M. Awake fibreoptic intubation. In: Difficult Airway Management. Popat M (ed). Oxford University Press, Oxford. 2009:65-76.

3. Woodall NM, Harwood RJ, Barker GL. Complications of a wake fibreoptic intubation without sedation in 200 healthy anaesthetists attending a training course. Br J Anaesth. 2008;100(6):850-855. doi: 10.1093/bja/aen076

4. Cafiero T, Esposito F, Fraioli G, Gargiulo G, Frangiosa A, Cavallo LM, et al. Remifentanil TCI and propofol TCI for conscious sedation during fibreoptic intubation in the acromegalic patient. Eur J Anaesthesiol. 2008;25(8):670-674. doi: 10.1017/S0265021508004195

5. Péan D, Floch H, Beliard C, Piot B, Testa S, Bazin V, et al. Propofol versus sevoflurane for fiberoptic intubation under spontaneous breathing anesthesia in patients difficult to intubate. Minerva Anestesiol. 2010;76(10):780-786.

6. Lallo A, Billard V, Bourgain JL. A comparison of propofol and remifentanil target controlled infusions to facilitate fiberoptic nasotracheal intubation. Anesth Analg. 2009;108(3):852-857. doi: 10.1213/ane.0b013e318184eb31 
7. Boehm CA, Carney EL, Tallarida RJ, Wilson RP. Midazolam enhances the analgesic properties of dexmedetomidine in the rat. Vet Anaesth Analg. 2010;37(6):550-556. doi: 10.1111/j.14672995.2010.00565.x

8. Belda I, Cubas MG, Rivas E, Valero R, Martínez-Pallí G, Balust J. Remifentanil target controlled infusion (TCI) vs ketamine or ketamine in combination with remi $\neg$ fentanil TCI for conscious sedation in awake fiberoptic intubation: A randomized controlled trial: 19AP1-5. Eur J Anaesthesiol. 2011;28:226.

9. Bürkle H, Dunbar S and Van Aken H. Remifentanil: a novel, short acting, mu opoid. Anesth Analg. 1996;83(3):646-651.

10. Cook TM, Woodall N, Frerk C, Fourth National Audit Project. Major complications of airway management in the United Kingdom. 4th National Audit Project of the Royal College of Anaesthetists and The Difficult Airway Society. Br J Anaesth. 2011;106(5):617-631. doi: $10.1093 / \mathrm{bja} / \mathrm{aer} 058$

11. Scholz J, Tonner PH. Alpha2-adrenoceptor agonists in anaesthesia: a new paradigm. Curr Opin Anaesthesiol. 2000;13(4):437-442.

12. Ralph Gertler, H. Cleighton Brown, Donald H. Mitchell, Erin N. Silvius. Dexmedetomidine: a novel sedative-analgesic agent. Proc (Bayl Univ Med Cent). 2001;14(1):13-21.

13. Paris A, Tonner PH. Dexmedetomidine in anaesthesia. Curr Opin Anaesthesiol. 2005 ;18(4):412-418. doi: 10.1097/01. aco.0000174958.05383.d5

14. Chopra P, Dixit MB, Dang A, Gupta V. Dexmedetomidine provides optimum conditions during awake fiberoptic intubation in simulated cervical spine injury patients. J Anaesthesiol Clin Pharmacol. 2016;32(1):54-58. doi: 10.4103/0970-9185.175666

15. Gerlach AT, Dasta JF. Dexmedetomidine:an updated review. The Annals of Pharmacotherapy. 2007;41:245-254. doi: 10.1345/ aph.1H314

16. Gertler R, Brown HC, Mitchell DH, Silvius EN. Dexmedetomidine: A novel sedativeanalgesic agent. Proc (Bayl Univ Med Cent). 2001;14:13-21.

17. Carollo DS, Nossaman BD, RamadhyaniU. Dexmedetomidine: a review of clinical applications. Curr Opin Anaesthesiol. 2008;21(4):457461. doi: 10.1097/ACO.0b013e328305e3ef

18. Scheinin B, Lindgren L, Randell T, Scheinin H, Scheinin M. Dexmedetomidine attenuates sympathoadrenal responses to tracheal intubation and reduces the need for thiopentone and perioperative fentanyl. Br J Anaesth. 1992;68(2):126-131.

19. Lawrence CJ, De Lange S. Effects of a single preoperative dexmedetomidine dose on isoflurane requirements and perioperative hemodynamic stability. Anaesthesia. 1997;52:736744.

20. Hall JE, Uhrich TD, Barney JA, Arain SR, Ebert TJ. Sedative, amnesic, and analgesic properties of small dose dexmedetomidine infu sions. Anesth Analg. 2000;90(3):699-705.

21. Bergese SD, Khabiri B, Roberts WD, Howie MB, McSweeney TD, Gerhardt MA. Dexmedetomidine for conscious sedation in difficult awake fiberoptic intubation cases. J Clin Anesth. 2007;19(2):141144.

22. Madhere M, Vangura D and Saidov A. Dexmedetomidine as sole agent for awake fiberoptic intubation in a patient with local anes 7 thetic allergy. J Anesth. 2011;25(4):592-594. doi: 10.1007/s00540-011$1154-\mathrm{z}$
23. Arcangeli A, D’Alò C, Gaspari R. Dexmedetomidine use in general anaesthesia. Curr Drug Targets. 2009;10(8):687-695.

24. He XY, Cao JP, He Q Shi XY. Dexmedetomidine for the management of awake fibreoptic intubation. Cochrane Database Syst Rev. 2014;(1):CD009798. doi: 10.1002/14651858.CD009798.pub2

25. Chu KS, Wang FY, Hsu HT, Lu IC, Wang HM, Tsai CJ. The effectiveness of dexmedetomidine infusion for sedating oral cancer patients undergoing awake fibreoptic nasal intubation. Eur J Anaesthesiol. 2010;27(1):36-40. doi: 10.1097/EJA.0b013e32832e0d2b

26. Saikat Niyogi, Samir Basak, Amita Acharjee, Indrani Chakraborty. Efficacy of intravenous dexmedetomidine on patient's satisfaction, comfort and sedation during awake fibre-optic intubation in patients with cervical spondylotic myelopathy posted for elective cervical fixation. Indian J Anaesth. 2017;61(2):137-143. doi: 10.4103/00195049.199856

27. Bekker A, Sturaitis MK. Dexmedetomidine for neurological surgery. Neurosurgery. 2005;57:1-10.

28. Cotecchia S, Kobilka BK, Daniel KW, Nolan RD, Lapetina EY, Caron MG. Multiple second messenger pathways of alphaadrenergic receptor subtypes expressed in eukaryotic cells. J Biol Chem. 1990;265:63-69.

29. Birnbaumer L, Abramowitz J, Brown AM. Receptor-effector coupling by G proteins. Biochim Biophys Acta. 1990;1031:163-224.

30. Metz SA, Halter JB, Robertson RP. Induction of defective insulin secretion and impaired glucose tolerance by clonidine. Selective stimulation of metabolic alpha-adrenergic pathways. Diabetes. 1978;27:554-562.

31. Virtanen R, Savola JM, Saano V,Nyman L. Characterization of the selectivity, specificity and potency of medetomidine as an alpha 2-adrenoceptor agonist. European Journal of Pharmacology. 1988;150:9-14

32. FDA HIGHLIGHTS OF PRESCRIBING INFORMATION, side effects and uses. Precedex.

33. FDA HIGHLIGHTS OF PRESCRIBING INFORMATION. DEXMEDETOMIDINE HYDROCHLORIDE injection, for intravenous use. Initial U.S. Approval: 1999.

34. Ebert TJ, Hall JE, Barney JA, Uhrich TD, Colinco MD. The effects of increasing plasma concentrations ofdexmedetomidine in humans. Anesthesiology. 2000;93(2):382-394.

35. Venn RM, Hell J, Grounds RM. Respiratory effects of dexmedetomidine in the surgical patient requiringintensive care. Criticical Care. 2000;4(5):302-308.

36. Maroof M, Knan RM, Jain D, Ashraf M. Dexmedetomidine is a useful adjunct for awake intubation. Can J Anaesth. 2005;52(7):776-777.

37. Hall JE, Uhrich TD, Barney JA, Arain SR, Ebert TJ. Sedative, amnestic, and analgesic properties of small-dose dexmedetomidine infusions. Anesthesia and Analgesia 2000;90:699-705.

38. Kamibayashi T, Maze M. Clinical uses of alpha2-adrenergic agonists. Anesthesiology. 2000;93:1345-1349.

39. Marisa Mariscal, Ma Luz Pindado, Alfonso Andueza Artal, José Ramón Cabañas Armesilla, Antonio García Rueda, Maite Portas, Oscar Valencia, Grupo Vía Aérea de Madrid. PROTOCOLO DE INTUBACION CON FIBROSCOPIO EN EL PACIENTE DESPIERTO. 2013.

40. Ramsay MA, Savege TM, Simpson BR, Goodwin R. Controlled sedation with alphaxalone-alphadolone. Br Med J. 1974;2(5920):656-659. 